Accepted version of: Jarvis, S. (2018). Practice-Focused, Constructivist Grounded Theory Methodology In Higher Education Leadership Research. In Theory and Method in Higher Education Research (Theory and Method in Higher Education Research; Vol. 4). Bingley: Emerald Group Publishing Ltd.. https://doi.org/10.1108/S2056-375220180000004012, https://doi.org/10.1108/S2056-375220180000004012

\title{
PRACTICE-FOCUSED, CONSTRUCTIVIST GROUNDED THEORY METHODOLOGY IN HIGHER EDUCATION LEADERSHIP RESEARCH
}

\section{Sal Jarvis}

\begin{abstract}
A growing body of education research considers practices, however there is less focus on a methodology that enables practical analysis of practices. Use of practice theory is growing, particularly in work and organisational studies, but practice focused studies more frequently address theoretical than methodological agenda. This chapter proposes a practice-focused, constructivist grounded theory methodology as one approach which can address this gap. After first considering the ways in which, separately and in combination, practice-theory and constructivist grounded theory can support higher education leadership and management research, the chapter considers implementation of this methodology by drawing on a study into the practice of authority in higher education leadership. It concludes by considering some implications for the ways in which practices can be understood and the affordances and limitations of this methodology.
\end{abstract}

Key words: social practice theory; constructivist grounded theory; higher education; leadership; management; authority

\section{INTRODUCTION}

Social Practice Theory (Reckwitz 2002) offers an alternative to structural and agentic perspectives on higher education research and a growing body of education research considers practices (see, for example Bolden et al. 2008, Wilkinson and Kennis 2015, Huber 2016). However, there is less focus on a methodology that enables practical analysis of practices, (Trowler (2013) is an exception). In this chapter I consider use of a practicefocused, constructivist grounded theory methodology in higher education leadership and management research. To do so I draw on aspects of my doctoral research into the practice of authority in academic leadership/management.

Interest in Higher Education leadership and management research has grown over the past decades (Tight 2012), driven by an increasingly performative government agenda (Deem and Brehony 2005, Ball 2013). While there is debate about theoretical models of leadership (Woods 2016), leadership characteristics (Lumby 2012) and leadership behaviour (Bryman 2007), methodological approaches are not always addressed in depth. Tight (2012) makes the point that it is not always easy to discern a clear methodological approach in higher education research, while Lumby (2012:2) considers that:

"The major part of the body of educational leadership research has an indistinct concept at the heart, [and] generally employs a narrow range of methods."

This chapter contributes to the debate by offering a methodological approach that focuses on understanding, not leaders themselves, nor theoretical models of leadership, but everyday actions and routines which enact leadership and followership (Raelin 2016). I argue that adopting a practice perspective (Schatzki 1996) combined with grounded theory 
Accepted version of: Jarvis, S. (2018). Practice-Focused, Constructivist Grounded Theory Methodology In Higher Education Leadership Research. In Theory and Method in Higher Education Research (Theory and Method in Higher Education Research; Vol. 4). Bingley: Emerald Group Publishing Ltd.. https://doi.org/10.1108/S2056-375220180000004012, https://doi.org/10.1108/S2056-375220180000004012

methods offers the possibility of constructing practices, including those relating to power (Watson 2017) and can therefore make visible some underpinnings of leadership and followership.

The chapter starts with a discussion of Social Practice Theory (Schatzki 1996), and Constructivist Grounded Theory (Charmaz 2014) and considers the synergies between the two. This is followed by a practical illustration, drawing on findings from my own doctoral research. I finish by considering the benefits and limitations of the approach, and by reflecting on some questions it raises for practice theorists.

\section{PRACTICE THEORY IN HIGHER EDUCATION LEADERSHIP/MANAGEMENT RESEARCH}

Massification of Higher Education (Watson 2011) has driven interest in Higher Education leadership and management research. Tight (2012) identified institutional management as one of eight key themes in Higher Education research. Different theoretical perspectives have been adopted. While some (for example, Ball 2012) highlight the extent to which academics are constrained by the commodified and performative system within which they find themselves, others have focused on the individual characteristics of institutional leaders. For example, Crawford (2012:611) highlights:

"... a strand of thinking about charismatic leadership that simply refuses to die."

Different views of human agency underlie these positions. Reckwitz (2002) outlines opposing alternatives: either human behaviour is largely a product of societal structures and the scope for agency is therefore very constrained, or individuals make rational decisions based on the information available to them to achieve the best for themselves; leaving extensive scope for individual agency. Arguments which suggest that academics are inevitably captured by a marketised discourse or consider managers/leaders' actions all but determined by institutional governance and structures seem predicated on a structuralist position, while arguments for the importance of visionary leadership seem built on a more agentic notion. Neither viewpoint, however, quite captures the complexity of the situation. On the one hand, as Trowler (2001) has suggested, academics are not completely captured by the discourse of managerialism, on the other, neither is their escape complete. Ball (2012:18) is surely right to say that dominance of a neo-liberal agenda in Higher Education: "...brings about a profound shift in our relationships, to ourselves, our practice, and the possibilities of being an academic."

Practice theory offers an alternative to this dichotomy by focusing attention on situated actions and understandings at a local level. Instead of seeing individuals and organisations, practice theorists see social processes (Nicolini 2012). For practice theorists, social structures are to be found in practices: patterned arrangements of related physical and mental actions, knowledge and material resources, meanings and emotions. As Nicolini (2017:107) remarks, practices "are always manifest in empirically accessible social sites of activity”. Practice theorists adopt a 'flat ontology' (ibid. 2017:99) which does not grant a special ontological status to macro social structures, but considers these constituted from everyday actions, objects and relations. Existing practices shape and constrain the actions of people who carry those practices, but practices are in turn changed by the actions of carriers.

This 'practice turn', as (Schatzki 2001) has described it, draws from the work of seminal theorists. Nicolini (2012) cites Nietzsche, Heidegger, Giddens, Bourdieu, Marx, Engeström, Garfinkel, Schatzki, Foucault, Lave and Wenger as contributing to a turn to practice in various ways. Clearly there is much that separates them, but what practice theorists have in 
Accepted version of: Jarvis, S. (2018). Practice-Focused, Constructivist Grounded Theory Methodology In Higher Education Leadership Research. In Theory and Method in Higher Education Research (Theory and Method in Higher Education Research; Vol. 4). Bingley: Emerald Group Publishing Ltd.. https://doi.org/10.1108/S2056-375220180000004012, https://doi.org/10.1108/S2056-375220180000004012

common is a focus on activities, both physical (including speech acts) and mental. It is the way that these separate activities are connected that forms a practice:

"... a routinized type of behaviour which consists of several elements interconnected to one another.... A practice - a way of cooking, of consuming, of working, of investigating ... forms so to speak a 'block' whose existence necessarily depends on the existence and interconnectedness of these elements..." (Reckwitz 2002:249)

These 'routinized blocks' are connected internally and to other 'blocks'. For example, Shove et al (2012:31) discuss driving a car:

"If we take the practice of driving a car rather than the car or the driver as the central unit of enquiry, it becomes clear that relations between the vehicle (along with the road and other traffic), the know-how required to keep it in motion and the meaning and significance of driving and passengering are intimately related, so much so that they constitute what Reckwitz refers to as a 'block' of interconnected elements."

The elements in the block are of various types and, while different authors focus on different aspects and may describe them rather differently, there is a reasonable degree of agreement about the classes of elements involved. For the purposes of this chapter, I follow Shove et al (2012) in adopting a simplified typology of elements which I have labelled routines, knowledge resources, material resources, actions and meanings.

Performances of practices connect situated knowledge and material resources, actions and meanings in a routinized way. Given that the actions undertaken in performances of practices will never be identical, it follows that practices are the site of change as well as routine (Hui 2017). The context bound nature of practices is crucial in understanding them. For example, the learning of teachers in the extract below is situated (Lave and Wenger 1991 ) in the context of that school's professional development programme at that particular time.

"All executives and teachers in staff meetings engaged in reading and then discussing shared professional development readings... Crucially, as relations of trust were built amongst staff and as a greater sense of collective responsibility for learning and leading emerged, readings were variously sourced by the principal, executive team members and teachers. As such, a shared language or set of 'sayings', i.e. ideas and understandings about particular pedagogical practices.... was gradually embedded over time." (Wilkinson and Kennis 2015:350)

This staff development practice brings together resources (the texts) and physical and mental actions (the act of reading and discussing the readings) together with meanings (trust and a sense of responsibility). This develops two aspects of shared knowledge: understanding of specific pedagogies and a feel for this particular mode of professional development. Adopting practices as one's unit of analysis in Higher Education leadership/management research can therefore help to explain social action and order: in this situation for example, why an established staff member who failed to share a reading might attract criticism, while a newcomer might not, at least initially.

However, analysing practices can be complex. Despite their situated nature, it is clearly possible to talk with understanding about practices (for example, 'driving', 'teaching' and 'leading') in the abstract. Shove et al (2012) distinguish practices as entities from practices as performances. They suggest that, existing as an abstract entity, practices also become a resource - a pattern - that can be drawn on in individual instantiations of a practice. Schatzki (1996) adds a further layer of complexity by differentiating what he calls 'integrated' 
Accepted version of: Jarvis, S. (2018). Practice-Focused, Constructivist Grounded Theory Methodology In Higher Education Leadership Research. In Theory and Method in Higher Education Research (Theory and Method in Higher Education Research; Vol. 4). Bingley: Emerald Group Publishing Ltd.. https://doi.org/10.1108/S2056-375220180000004012, https://doi.org/10.1108/S2056-375220180000004012

from 'dispersed' practices. While both are situated, he suggests that integrated practices are situated in a specific context and would commonly - like teaching or football- utilise a familiar set of material resources. Dispersed practices - like questioning or ordering- may occur in a wide range of situations but are, he argues, recognisable by practitioners as an instantiation of that practice.

All of this offers much to the researcher of Higher Education leadership and management: the situated, inter-connected nature of practices aligns well with a conception of leadership as context bound and relational, the focus on actions aligns with research interest in what it is that leaders do, while adopting practices as the unit of analysis offers an alternative to the structure-agency dilemma. So, which methodological approaches might best support a focus on practices as the unit of analysis? Trowler (2013) suggests ethnography as one such tool. Below I argue that constructivist grounded theory is another.

\section{CONSTRUCTIVIST GROUNDED THEORY}

To understand practices in Higher Education leadership and management a methodological approach which enables focus on practices and their elements is needed. Grounded Theory is promising in this respect because it focuses on actions rather than structures:

"[Strauss] assumed that process, not structure, was fundamental to human existence.... the construction of action was the central problem to address." (Charmaz 2014:9)

Developed by Glaser and Strauss (1967) in response to the domination of quantitative research within a positivistic paradigm, the aim of Grounded Theory was to offer a robust methodology which relied on neither a logico-deductive approach, nor on rigorous hypothesis testing and statistical analysis of quantitative data, but on a process of comparative analysis through detailed coding (Glaser and Strauss 1967: 1-6). Theory, they argued, should emerge from the data. Prior hypotheses were eschewed: the researcher should enter the field without preconceptions. An important principle in Grounded Theory was the idea that data collection, coding and analysis should take place contemporaneously, through an iterative process, rather than sequentially. As soon as data was collected it was closely coded line by line, focusing on actions by using gerunds to form codes. These early codes then shaped subsequent data collection, through a process labelled theoretical sampling (Glaser and Strauss 1967:45). At all stages of data collection and analysis memos were written to capture and interrogate emerging categories.

It is important to say that classic Grounded Theory has been extensively critiqued. Charmaz (2014:12) points out that it depended on:

"...mid-century assumptions of an objective external reality, a passive, neutral observer [and] a detached, narrow empiricism."

Thomas and James (2006) saw this as predicated on an outdated notion of an objective, empirically discoverable social world. Further, Lempert (2007) points out the impossibility of researching without pre-conceptions:

"In order to participate in the current theoretical conversation, I must understand it." (Lempert 2007:254)

These criticisms have considerable force. However, if one steps away from the insistence on the researcher as a tabula rasa with an objectivist stance, then grounded theory may have potential to be useful to practice theorists. Bryant and Charmaz (2007) developed a constructivist Grounded Theory in which findings are conceived as constructed from, rather 
Accepted version of: Jarvis, S. (2018). Practice-Focused, Constructivist Grounded Theory Methodology In Higher Education Leadership Research. In Theory and Method in Higher Education Research (Theory and Method in Higher Education Research; Vol. 4). Bingley: Emerald Group Publishing Ltd.. https://doi.org/10.1108/S2056-375220180000004012, https://doi.org/10.1108/S2056-375220180000004012

than emerging from the data. The place of the researcher then becomes central in the research. They argue that researchers, therefore, should bring an understanding of the literature to their research and that 'sensitising concepts' can be helpful in analysis as long as they are not used to predetermine codes. In addition to the notion of sensitising concepts, three aspects of Constructivist Grounded Theory can be valuable in a practice approach. Charmaz (2014:15) sums up nicely: constructivist grounded theorists:

"1. Conduct data collection and analysis simultaneously in an iterative process

2. Analyse actions and processes rather than themes and structure

3. Use comparative methods..."

The following paragraphs consider each of these in turn.

The iterative approach taken by grounded theorists can support identification of hidden practices. Shove et al (2012:17) offer the example of snowboarding to illustrate analysis of practices through a focus on elements. In this example, one might imagine, it would be relatively easy to find data to collect; one simply needs to go and observe snowboarding in action. However, as we have seen, Schatzki (1996:91-98) proposes two categories of practices: integrated and dispersed. While integrated practices (like snowboarding) are situated in specific domains (such as the Olympics), the latter (like ordering) occur widely 'across different sectors of social life'. Heimans (2012:383) suggests that a key difference between integrated and dispersed practices is that integrated, but not dispersed, practices have explicit rules. If this is the case, then finding and observing practices is not simple if they are dispersed. Even for integrated practices, however, things are complex. For example, there are variants of snowboarding such as freeriding and competing (Shove et al: 106). To understand these nuanced practices, understanding must be built step by step. Furthermore, practices of power (which leadership and management practices may be) are likely to be carried on 'under the stage' to a degree. For example, Lipsky (1980) identified the ways in which social security staff in the USA practiced their (limited) authority to restrict access to benefits and subvert policy makers' plans. An iterative approach, in which researchers follow up early, open coding with purposive sampling that enables a potential category to be built and tested, could support the construction of hidden practices.

A second benefit of constructivist grounded theory is the focus on processes and actions. Use of gerunds (deciding, supporting, challenging etc.) in coding can help to ensure that the researcher stays grounded in actions and processes, rather than, for example, looking for cross-cutting themes. This, coupled with use of sensitising concepts to interrogate data can be used to support construction of practices. In my doctoral research I adopted elements of practices (Shove 2012) as a framework to surface routinised practices following initial coding.

Finally, Constructivist Grounded Theory's comparative approach is also helpful in surfacing routines. It allows researchers to compare actions, meanings, knowledge and material resources in different events to identify the recurring behaviours (Reckwitz 2002) that characterise practices. Comparison in early coding suggests conceptual categories which can enable the researcher to collect further data through theoretical sampling that tests each category.

To sum up so far: making practices the unit of analysis in leadership/management research in Higher Education enables a focus on the actions and relations of leadership/followership. Understanding practices requires researchers to construct from data the everyday routines that are made up of actions, knowledge, materials, meanings and emotions. Constructivist grounded theory method, by adopting an iterative, comparative approach which focuses 
Accepted version of: Jarvis, S. (2018). Practice-Focused, Constructivist Grounded Theory Methodology In Higher Education Leadership Research. In Theory and Method in Higher Education Research (Theory and Method in Higher Education Research; Vol. 4). Bingley: Emerald Group Publishing Ltd.. https://doi.org/10.1108/S2056-375220180000004012, https://doi.org/10.1108/S2056-375220180000004012

closely on mental and physical actions offers a practical tool with which to surface the everyday practices of power and leadership. The following section of this chapter considers a practical example of this from my own doctoral research (Jarvis 2017).

\section{CONSTRUCTING AUTHORITY IN ACADEMIC LEADERSHIP/MANAGEMENT}

My doctoral research (Jarvis 2017) sought to advance understanding of authority in Higher Education academic leadership/management. Although there is rich literature on education management and leadership, the role of authority in this area has received less attention. Drawing on an understanding of authority as social, multiple, changeable and contested, my research had three broad aims: to understand contextualised authority practices; to conceptualise authority in academic leadership/management and to investigate the value of practice-focused, constructivist grounded theory methodology in educational research. Data were collected from the Education Departments of two, Post-1992, UK universities (which I titled 'Hefton' and 'Rockborough') over a period of eighteen months and analysed using elements of practices as a sensitising framework. The study showed how elements combined in construction of authority. Three practices: overseeing, deciding and challenging, were constructed. Findings contributed to understanding the complexity of authority practices in this domain. For the purposes of understanding the methodology, in this chapter I focus only on 'deciding' as a practice, and on construction of knowledge as an element in decision making.

\section{Using the literature}

I adopted an iterative approach to reviewing the literature, combining this with data collection and analysis. I was conscious that the literature contained useful examples of data on leadership/management practices in other Higher Education settings. However, since practices are embodied in performances (Shove et al. 2012) a focus on situated instantiations of practices was needed. Data from other studies could cast light on my own data but must not force analysis. I therefore used the literature in three ways: firstly, as an iterative literature review, developed alongside data collection and analysis, and driven by emerging categories; secondly, to identify and analyse examples of practices described in the literature, in order to deepen analysis of my primary data; and finally, in a closer analysis of publications on academic management and leadership written by academics in the departments I was researching. The examples below illustrate this.

- I reviewed the literature on authority after initial coding. I then revisited data to examine them from the perspective of this literature. Some codes strongly reflected themes within the literature. For example, Blencowe (2013) considers access to knowledge key in authority. 'Knowledge', and references to access, were frequent codes in early analysis.

- I carried out analysis of management/leadership practices included as examples in Higher Education leadership and management literature. Actions included monitoring, attending meetings, giving news, signing off, supporting and holding privileged knowledge (Jarvis 2017: 85). Each was also evident in my data.

- Publications by academics in the two departments highlighted practices at the borderline between resistance and compliance, and the ways in which leadership styles might conceal power practices. To preserve confidentiality, I have not referenced these. 
Accepted version of: Jarvis, S. (2018). Practice-Focused, Constructivist Grounded Theory Methodology In Higher Education Leadership Research. In Theory and Method in Higher Education Research (Theory and Method in Higher Education Research; Vol. 4). Bingley: Emerald Group Publishing Ltd.. https://doi.org/10.1108/S2056-375220180000004012, https://doi.org/10.1108/S2056-375220180000004012

\section{Coding}

Initial coding focused on identifying actions (Charmaz 2014) through the use of gerunds. By not working from pre-constructed, theoretical codes, I was able to remain at the level of the data. This produced several hundred codes relating to actions, only some of which were anything to do with authority. Therefore, as I started to re-code data through focused coding, I looked explicitly for apparent instances of assertion of, or deference to, authority. I reviewed the literature on authority as I re-coded, conscious that my understanding would shape what I noticed (Mason 2002). To avoid forcing the data I needed a working definition of authority which was to some extent indistinct, so that I limited imposition of my own preconceptions. Wittgenstein (1953: $§ 70$ ) discusses the concept of a game. He asks "... do you want to say I don't know what I am talking about until I can give you a definition?" It is a rhetorical question, of course, and he answers himself:

"One might say the concept of a 'game' is a concept with blurred edges. - 'But is a blurred concept a concept at all?' - Is an indistinct photograph a picture of a person at all? Is it even always an advantage to replace an indistinct picture by a sharp one? Isn't the indistinct one often exactly what we need?" (Wittgenstein 1953: §71)

An indistinct definition of authority was exactly what I needed: focused enough to allow me to recognise potential instances of authority, yet flexible enough to cast my net widely. I therefore drew on a wide range of typologies of foundations of authority (Arendt 1961, Raz 1990, Weber 2004, Blencowe 2013, Woods 2016) without privileging any.

Following grounded theory method, I coded line by line. Early codes focused on the physical and mental actions of academic managers/leaders and staff. Examples of codes that later related to decision making included deciding hours, introducing change in meetings, emailing round for ideas. Figure 1, where a deputy head of department is explaining a decision to radically change the curriculum and pedagogical approaches in one degree, illustrates my coding:

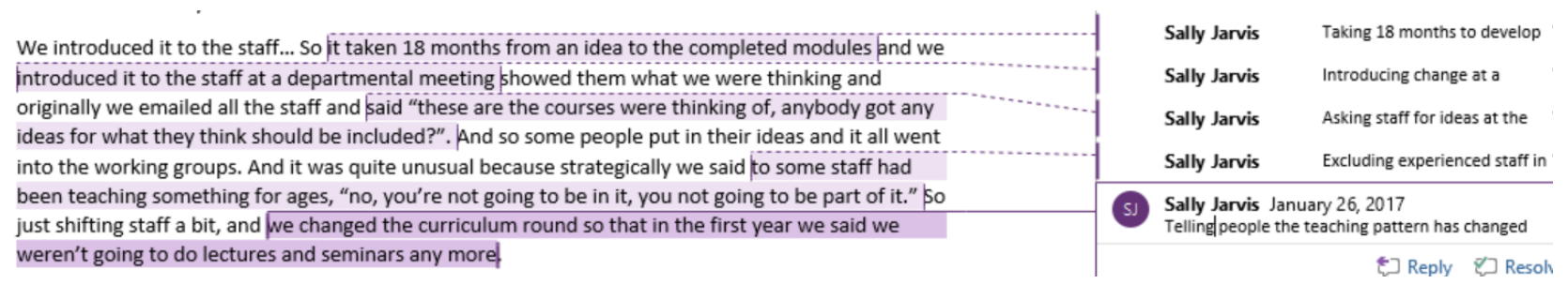

Figure1: coding with gerunds

Having grounded initial analysis in actions I needed to analyse the ways in which other elements of practice were evident in data. Charmaz (2014:30) writes:

"Grounded theorists use sensitising concepts as tentative tools for developing their ideas about processes that they define in their data."

I adopted other elements of practice (meanings, emotions, materials, routines and knowledge) as sensitising concepts. In focused coding I looked for examples of these elements. Not all were evident: codes relating to meanings and emotions were too limited to construct clear categories. However, codes relating to knowledge and material resources were common and several categories were constructed from each of these elements. Sometimes it was hard to decide on a category. However, while categories' edges were blurred and over-lapping they recurred persistently enough in the data to warrant individual consideration. 
Accepted version of: Jarvis, S. (2018). Practice-Focused, Constructivist Grounded Theory Methodology In Higher Education Leadership Research. In Theory and Method in Higher Education Research (Theory and Method in Higher Education Research; Vol. 4). Bingley: Emerald Group Publishing Ltd.. https://doi.org/10.1108/S2056-375220180000004012, https://doi.org/10.1108/S2056-375220180000004012

Further comparison supported construction of routines, and then practices. By comparing data around similar codes I was able to identify clusters where codes appeared together commonly: material resources, sequences of actions and knowledge resources that occurred together suggested routines. These linked with other routinised actions and formed practices that overlapped and merged, one into another, linked by elements (Shove et al. 2012). Caution was needed: practice boundaries are to a degree arbitrary, constructed by the researcher. Further, one must be wary of extrapolating. These labels can apply only to these specific practices in these contexts. However, notwithstanding these caveats, clusters of routinised actions, linked with knowledge and material resources, recurred within the data. My research focused on construction of three practices: overseeing, challenging and deciding. These three were not the only practices that emerged from comparison- 'giving' was another - but they were the most strongly recurring.

\section{Constructing the elements of practices}

This section looks briefly at construction of the elements of practice. My aim is to show how focused coding, using a sensitising framework and iterative literature review, can enable construction of categories. To do so, I focus on construction of categories of knowledge. The literature points to the importance of knowledge in establishing authority (Weber 2004, Blencowe 2013). Practice theorists also highlight the importance of situated knowing in practice. Schatzki (2001) talks about practical intelligibility and understandings; Reckwitz (2002) refers to know-how, knowledge and understanding; Shove et al (2012) refer to competencies, skills, know-how and technique and Trowler (2013) talks about practical skills, knowing how to go on, intelligibility and a feel for the game. Given this it is unsurprising that knowledge-focused codes were prevalent. Several categories of knowledge were constructed of which two, 'knowing what is going on' and 'using professional and disciplinary expertise', were evident in operational decision making.

One cluster of codes suggested professional expertise (Weber 2004) as a source of authority. This was evident in multiple references to professional and disciplinary expertise as a knowledge resource. Close coding and further theoretical sampling filled out the categories. Data suggested ways in which managers/leaders drew on professional knowledge to achieve compliance from others and to explain their own deference to the authority of professional standards. For instance, codes from data at Hefton ('It was just the world I was in" and "what I did every day') suggested managers drew on past, target driven, professional practice to justify a decision to ask staff to teach longer hours.

“.... Having to measure outcomes, much more like KPUs. They are like, 'what are they?' Everything is so new. Whereas I was target driven and everything was measured. It was just the world I was in.... I was working with young people from nine until three every day. And even now, I have a smile because, like a member of staff was saying, 'I had to teach six hours yesterday'. And I thought, 'Well, that's what I did every day!'. And I still find that quite hard...yes, so they moan but I still think, 'Be glad you're not a teacher because they have it a lot harder.'

(Extract 1: Hefton)

I also drew on the literature to fill out categories. Blencowe (2013) argues that to speak with authority is to point beyond oneself to some objectivity (not necessarily truth). Being able to define which knowledge counted (agenda setting) appeared to be an important element in this (Bachrach and Baratz 1962). At Hefton, as the extract above shows, the knowledge that counted was teaching knowledge. In extract 2 those with non-university teaching expertise 
Accepted version of: Jarvis, S. (2018). Practice-Focused, Constructivist Grounded Theory Methodology In Higher Education Leadership Research. In Theory and Method in Higher Education Research (Theory and Method in Higher Education Research; Vol. 4). Bingley: Emerald Group Publishing Ltd.. https://doi.org/10.1108/S2056-375220180000004012, https://doi.org/10.1108/S2056-375220180000004012

are identified as 'the best teachers', while having disciplinary experience ("straight from PhDs") is linked by a manager to ignorance about teaching and poor practice.

"Most people have got professional experience before coming in here. They're the best teachers. It's the ones who have come straight from a PhD who tend to be the worst. Often because that's the way they've been taught themselves and they've never seen anything else."

(Extract 2: Hefton)

Constant comparison of similar codes helped to fill out categories while I moved between the two institutions. For example, at Hefton, while past professional knowledge (teaching) conferred authority, academic disciplinary knowledge did not. In contrast, this was identified by several participants at Rockborough as a source of authority.

"I think that's based on values, isn't it? I mean framing descriptors and criteria within a policy comes from what you believe ...I think that comes from an academic authority which also stems from confidence in oneself as an academic. And an academic leader at that."

(Extract 3: Rockborough)

Another member of staff at Rockborough referred to their recently completed doctorate as giving 'that bit of authority'. These comparisons highlighted the situated nature of practices. While professional knowledge resources were valuable in establishing authority in both institutions, the nature of valuable knowledge was distinctive to each.

These institutional differences were evident in many categories. A second cluster codes I labelled 'knowing what is going on' after a repeated in vivo code. It included understanding local data as well as grasping internal politics. When a manager remarked, of his line manager, "I've found the less she knows the better to be honest" and of staff, "I learned where the power bases were', he revealed the power of 'knowing what is going on'. At Hefton knowledge of student perceptions/satisfaction/wants was accorded a central position ('...they pay our wages you know, we want happy students.'). Focused codes connected knowledge of students' wants to management/leadership decision making. In extract 4 a decision is driven by student perception data ("...there was no question ...") so that access to this knowledge appears to trump any other argument:

"And he said, 'right, what are we getting from the students?' And we said, right, from the surveys they are asking for this, and this, and this, and there was no question from my head of department because he is very student orientated. He was like, 'Well, we've got to do it then.'

(Extract 4: Hefton)

By contrast at Rockborough, 'knowing what is going on' referred more often to knowledge acquired from universities' senior managers/leaders. The phrase 'it came from the Vice Chancellor/Deputy Vice Chancellor/very senior people' was common. Managers/leaders attended faculty and university level committees and referred to representing their school/department as well as 'reporting back'. In this process they learnt about what was going on outside their own unit and were put in a position of being able to choose what information to share. 
Accepted version of: Jarvis, S. (2018). Practice-Focused, Constructivist Grounded Theory Methodology In Higher Education Leadership Research. In Theory and Method in Higher Education Research (Theory and Method in Higher Education Research; Vol. 4). Bingley: Emerald Group Publishing Ltd.. https://doi.org/10.1108/S2056-375220180000004012, https://doi.org/10.1108/S2056-375220180000004012

"And I mean, each of us has different responsibilities to go to Faculty meetings and our responsibility is then to represent the School at the faculty and then bring anything back to the School."

(Extract 5: Rockborough)

The power that could attach to this restricted knowledge was considerable. At Hefton, student outcomes and perception data drove performance management (extract 6). Inequality of access to objective knowledge: ('come directly to me') enabled managers to use privileged access to start conversations with staff.

"You know [Hefton] is really good at data. I can find data on pretty much anyone's performance... we've got the course evaluations which come directly to me ...So there's no shortage of data. If there's an issue we pick it up quite quickly."

(Extract 6: Hefton)

The prevalence of codes for access to knowledge (Blencowe 2013) led me to reflect on practice theory itself: specifically, the nature of knowledge as an element in practices. My theoretical sampling in later interviews sought, inter alia, to explore this question. My sensitising framework was therefore helpful in understanding practice theory. It had been important to me that the framework did not force categories: an unexpected bonus was that using the elements of practice as a tool for analysis supported critique of the elements themselves.

\section{Constructing practices}

Having developed categories of knowledge and material resources, I then revisited data to identify repeated sequences noting, in memos, the codes that seemed to form an interconnected block (Reckwitz 2002). This was more complex than I had anticipated. While it was relatively easy to identify common routines (for example I constructed categories such as 'emailing', 'following systems' and 'meeting') these, in themselves, did not seem to capture practices of authority. Ultimately, I followed a two-stage process, first constructing categories relating to 'everyday routines', including those referred to above, and then revisiting the data armed with the 'indistinct definition' of authority referred to earlier in this chapter. This led to the construction of three authority practices built from blocks of interconnected routines, knowledge and material resources (Reckwitz 2002). Here, I illustrate construction of authority practices with reference to one practice, 'deciding' with one example from each institution: a decision to change teaching patterns at Hefton and a decision about which researchers to submit for the Research Excellence Framework (REF) the UK government's process for deciding research funding- at Rockborough.

Using Schatzki's (1996) definition, 'deciding' may be considered a dispersed practice: 'performances' of decision making do not have specific locales or resources but are nonetheless recognisable by practitioners as decisions. In this present context, 'deciding' refers specifically to an authority practice in higher education academic management/leadership. This is only one practice alongside many other practices of deciding (such as deciding what to wear, deciding whether to take an umbrella and so on), some of which may be connected to authority and some not.

Coding of clusters of actions enabled me to outline stages in decision-making (figure 2). The overall sequence of actions at both institutions was similar. In both, "knowing what was going on" was an important element. For both, this included understanding of external drivers (for 
Accepted version of: Jarvis, S. (2018). Practice-Focused, Constructivist Grounded Theory Methodology In Higher Education Leadership Research. In Theory and Method in Higher Education Research (Theory and Method in Higher Education Research; Vol. 4). Bingley: Emerald Group Publishing Ltd.. https://doi.org/10.1108/S2056-375220180000004012, https://doi.org/10.1108/S2056-375220180000004012

example regulatory structures) and internal data. In making operational decisions management/leadership teams in both institutions used privileged access to this knowledge to develop a proposed course of action. In both, the decision-making processes made use of familiar routines and the decision was communicated in familiar ways to staff. Normally, efforts were made to involve staff in some way. Accounts suggested that knowledge seeking was commonly part of this initial communication: either to gather information from staff or to request staff input of ideas. Knowledge gained was reviewed by managers/leaders, or by groups established by them. Following this a decision was made. Sometimes this decision was tentative and was passed on to other parts of the university for approval and/or returned to staff for further comment. Only after support was secured was the decision announced, normally by a person with positional authority. Finally, further steps were taken to engage with and support staff, particularly those who might be unhappy with the decision.

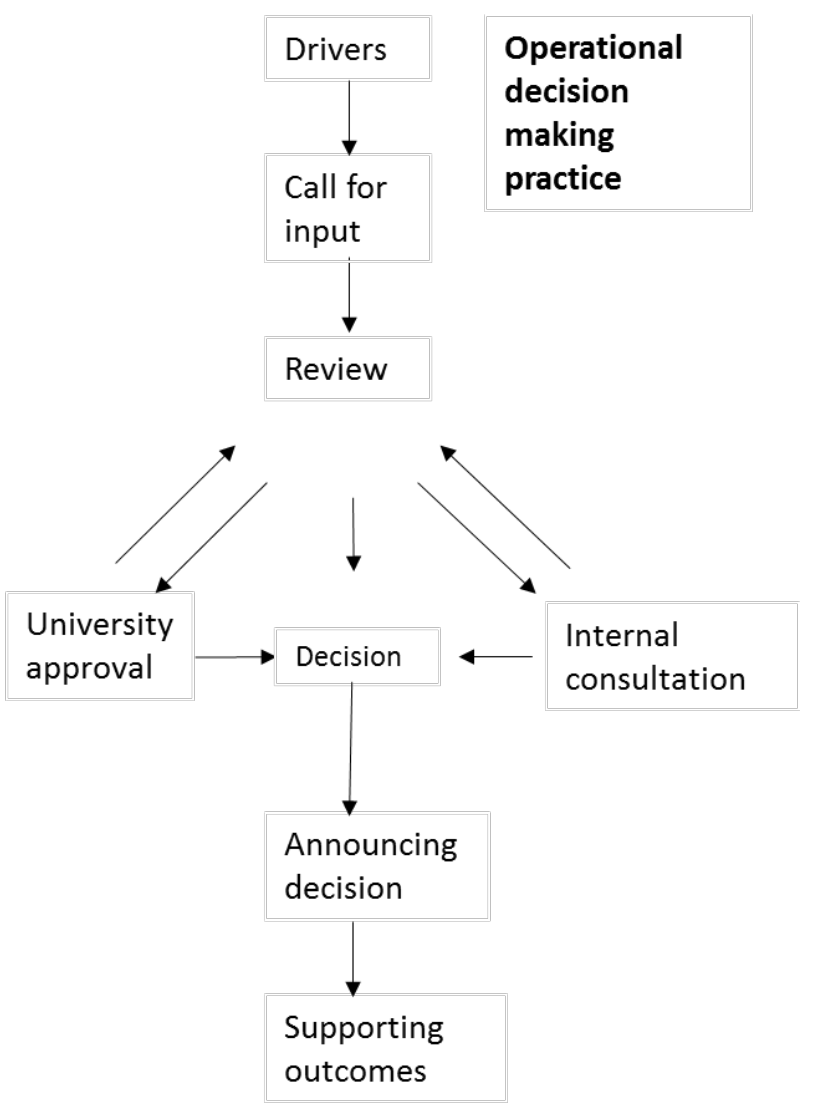

Figure 2 decision making

While elements in decision-making remained constant; suggesting that Figure 2 represents a practice entity (Shove et al 2012), the ways in which these were filled out varied. At Hefton, a decision to change teaching patterns drew on familiar routines. The change took place as part of the university's periodic review process and was therefore unlikely to be resisted by staff, once agreed. Staff meetings helped consolidate the decision. Management/leadership staff at Hefton were ambivalent about the use of email ('there's death by email'/ 'you can get the tone wrong') and therefore did much face to face in one to one, team based or departmental meetings. Data at Hefton referenced 'casual conversations along the corridor' and these, as well as 'more formal meetings' were used. Including these routines embedded the decision in familiar practices and helped, therefore, to normalise it. 
Accepted version of: Jarvis, S. (2018). Practice-Focused, Constructivist Grounded Theory Methodology In Higher Education Leadership Research. In Theory and Method in Higher Education Research (Theory and Method in Higher Education Research; Vol. 4). Bingley: Emerald Group Publishing Ltd.. https://doi.org/10.1108/S2056-375220180000004012, https://doi.org/10.1108/S2056-375220180000004012

In keeping with Hefton's focus on students, knowledge resources were focused on student experience and staff teaching expertise. The ways in which knowledge resources were used at Hefton was key in assuring that the decision was deferred to by staff. Firstly, knowledge was underpinned by a shared understanding of Higher Education as marketised and target driven (that 'what students want' was important and that government drivers mattered). Secondly, those in positional authority had best access to knowledge, partly because they had access to material resources (such as university finance documents or student data) that were restricted, but also because were best able to define what knowledge should count (agenda set). The management/leadership team used these 'inequalities of access to objectivity' (Blencowe 2013:10) to define which knowledge counted and ensure that their decision was deferred to.

At Rockborough 'making a case' (report writing) featured heavily and the decision about which academics' work to submit to the Research Excellence Framework made significant use of written assessments from internal as well as external reviewers. Staff at Rockborough viewed emails more positively than those at Hefton and so emails were used to communicate. The nature of valuable knowledge differed too. For example, in keeping with the value placed on disciplinary expertise at Rockborough, an advisory group of experienced researchers was established. The advisory group's access to expert knowledge shaped decisions: for example, knowledge of the government funding formula was used in decision making to classify some research as 'a load of one and two-star stuff'. Practices as performance (Shove et al 2012) therefore varied dependant on which routines, knowledge and material resources were available and valued.

This brief illustration highlights the potential of the methodology. Using an approach which enabled focus on the elements of practice facilitated tentative construction of abstract practice entities and as well construction of specific practice performances, thus highlighting both commonality and difference in higher education practices.

\section{DISCUSSION AND CONCLUSION}

One of my aims in adopting a practice focused, constructivist grounded theory methodology was to shine a light on components of the methodology itself. This section considers potential benefits, limitations, and some unresolved questions. I have tried not to tidy away loose ends but rather to make them visible in the hope that others will pick them up and work with them.

\section{Benefits of a practice-focused, constructivist grounded theory approach}

One benefit of the approach is its power as a practical tool. In this methodological approach, Social Practice Theory is used both as a theoretical perspective and as a tool for data analysis. This, combined with Grounded Theory method's iterative approach to data collection, its focus on actions and processes, and use of constant comparison, supports the construction of practices in Higher Education. This enables a less agentic and more relational understanding of data, in which actions and interactions, resources and meanings, rather than people and their perceptions, are the focus of analysis. Since one criticism (Lumby 2012) of some research into higher education management/leadership has been that there can be undue focus on leaders themselves, this is helpful in broadening the debate.

Shove et al. (2012) distinguish practices as performances from practices as entities. Analysis of the findings from my study suggests that this methodological approach supports construction of both, and consequently has explanatory power. Analysis that looks for repeated clusters of the elements of practice enables construction of practice entities, while 
Accepted version of: Jarvis, S. (2018). Practice-Focused, Constructivist Grounded Theory Methodology In Higher Education Leadership Research. In Theory and Method in Higher Education Research (Theory and Method in Higher Education Research; Vol. 4). Bingley: Emerald Group Publishing Ltd.. https://doi.org/10.1108/S2056-375220180000004012, https://doi.org/10.1108/S2056-375220180000004012

examination of each cluster surfaces the differences between instantiations. For example, if we look at use of knowledge resources in decision-making, we see that deciding, as a practice entity, was formed from repeated sequences of codes (figure 2), coupled with similar categories of knowledge (for instance 'professional and disciplinary knowledge'). Early coding that constructed broad categories of knowledge then enabled a finer-grained analysis of the ways that access to specific knowledge resources filled out decision making in performances. Individual performances of deciding drew differently on professional and disciplinary knowledge. How authoritative decisions were made at each institution can therefore be explained with reference to these practices.

Shifting research focus from leaders' perceptions to the construction of practices by analysing the actions of leaders and followers, and the knowledge and material resources that they draw on, has the potential to explain action, stasis and change in universities.

Because practice theory focuses on routines it can illuminate how actions become routinized and why unhelpful practices that both managers and staff reject might persist as they become embedded as integral parts of other practices. Because individual performances of practices are filled out in different ways a grounded theory analysis makes it possible to see how practices may change over time - and perhaps to understand how changing aspects of practice, for example changing access to material and knowledge resources, may be used to support change in Higher Education practice.

\section{Illuminating aspects of practice theory}

The practicalities of coding and constructing categories of elements and practices gave insight into some tensions and complexities. Here I consider two aspects of this: the status of knowledge as an element in practices, and the complexity of defining practice boundaries.

Knowledge is identified as a key element in practices (Shove, Pantzar et al. 2012, Trowler 2013). Certainly, knowledge based codes were prevalent in my analysis. However, there was a sense in which knowledge was drawn on as a resource by practitioners, in the same way that they drew on other, material, resources. Knowledge was used as a tool to establish (or defer to) authority. Access to resources - knowledge or material, was instrumental in the practice of authority. Restricting or giving access to knowledge resources was an important part of the practice of authority, in the same way that restricting or giving access to material resources could give one member of staff authority over another. Blencowe (2013:10) talks about 'access to objectivity', to highlight the idea that defining what knowledge counts is itself a construction of power. Since one concern is that power may be ignored when practice theory is applied to organisations (Contu and Willmott 2003) a methodological approach that enables a focus on access may be helpful. Perhaps a practice approach should focus as much on access to resources as on the resources (whether knowledge or material) themselves?

A second question related to the relationship between routinised actions and practices. As I have outlined above, routines and practices were constructed in a two-stage process, following my coding for actions and construction of categories of knowledge and material resources. Actions and resources emerged directly from focused coding, whereas routines gained significance from arrangements of actions and resources and from the ways in which these were interpreted by practitioners. Both routines and practices, therefore, emerged from constant comparison of the juxta-positioning of codes relating to actions, knowledge and material resources. Reckwitz (2002) describes practices as routinized actions, suggesting routines embedded into larger practices could themselves be considered practices: for example, in the practice of 'deciding', practitioners drew on familiar routines (practices) around meetings and emails. However, these practices could then also be sub-divided: 
Accepted version of: Jarvis, S. (2018). Practice-Focused, Constructivist Grounded Theory Methodology In Higher Education Leadership Research. In Theory and Method in Higher Education Research (Theory and Method in Higher Education Research; Vol. 4). Bingley: Emerald Group Publishing Ltd.. https://doi.org/10.1108/S2056-375220180000004012, https://doi.org/10.1108/S2056-375220180000004012

'meeting' being constructed from smaller practices of 'sending an agenda' or 'taking minutes' (two codes from my data analysis). But could this regression then continue ad infinitum: if so, then what, in the end, do we call a practice? More work to explore embedded practices and the ways in which routines/practices overlap and interact would be interesting.

\section{Limitations and challenges}

My conundrum around the boundaries of practices connects with one of the limitations of constructivist grounded theory, which is that any construction is logically shaped by the person constructing it. As Charmaz (2014:29) says:

"People construct data - whether it be researchers generating first hand data through interviews or field notes..." (Author's emphasis)

Additionally, grounded theory method often draws, as I did, on intensive interviews (Charmaz 2014:18). While this can give access to situations that an observer could not easily access, it introduces a double hermeneutic, as data are seen through two filters, so that where one practice seems to stop, and another starts, is constructed from the utterances and perceptions of practitioners and researchers. Brinkmann (2013:4) likens using interviews in a world filled with conversations to a fish studying water.

This means that it is crucial to keep in mind that practices are devices, ways of describing the mental and physical, routinised actions of practitioners. Practices do not have separate ontological realities. Where practice boundaries begin and end may therefore be a pragmatic, rather than an ontological, discussion which necessarily reflects the personal and theoretical perspectives of those who are doing the describing.

A second limitation was that meanings did not emerge as a significant set of codes from my data, although they were present to some degree. Sometimes the juxta-positioning of words (for example 'tough' and 'teaching' at Hefton), suggested meanings, but these were not as clear as other elements. This does not mean, of course, that meanings are not relevant as an element in practice - this seems very unlikely- but, more likely, that this methodology was not effective in constructing meanings. One reason for this might be the methodology's focus on actions, leading to neglect of other aspects of the text: for example, coding did not focus on the manner of delivery (repetitions, hesitations, emphases and so on). It would be interesting to revisit the data with this focus. Watson (2017) suggests discourse analysis as a methodology for surfacing practices of power. Alvesson and Karreman (2000:1133) consider discourse analysis valuable in organisational research, identifying four levels of analysis, micro, meso, grand and mega discourse. Micro discourse analysis, which focuses on social texts in a micro context, and includes analysis of the manner of discourse might be used alongside the current analytical approach to enable meanings to emerge more clearly.

\section{In conclusion}

Notwithstanding these notes of caution, it seems to me that a practice-focused, constructivist grounded theory methodology has potential to be a useful tool in Higher Education research. It offers a practical tool for construction of practices through analysis of relationships between actions, knowledge and resources that can complement adoption of practice theory as a theoretical perspective. 
Accepted version of: Jarvis, S. (2018). Practice-Focused, Constructivist Grounded Theory Methodology In Higher Education Leadership Research. In Theory and Method in Higher Education Research (Theory and Method in Higher Education Research; Vol. 4). Bingley: Emerald Group Publishing Ltd.. https://doi.org/10.1108/S2056-375220180000004012, https://doi.org/10.1108/S2056-375220180000004012

\section{REFERENCES}

Alvesson, M. and Karreman, D., 2000. Varities of discourse: On the study of organizations through discourse analysis. Human Relations, 53(9), pp. 1125-1149.

Arendt, H. (1961). What is authority? Between Past and Future. London, Faber and faber: 91-141.

Bachrach, P. and Baratz, M.S. (1962). "The two faces of power." American political science review 56: 941-952.

Ball, S. (2012). "Performativity, Commodification and Commitment: an I-spy guide to the neo-liberal university." British Journal of Educational Studies 60(1): 17-28. DOI:

10.1080/00071005.2011.650940

Ball, S. (2013). Foucault, Power and Education. London, Routledge.

Blencowe, C. (2013). "Biopolitical authority, objectivity and the groundwork of modern citizenship." Journal of Political Power 6(1): 9-28.DOI: 10.1080/2158379X.2013.774968

Bolden, R., Petrov, G. and Gosling, J. (2008). "Tensions in Higher Education Leadership: Towards a Multi-Level Model of Leadership Practice." Higher Education Quarterly 62(4): 358-376. DOI: 10.1111/j.1468-2273.2008.00398.x.

Brinkmann, S. (2013). Qualitative interviewing. New York, OUP.

Bryant, A. and Charmaz, K. (2007). The Sage Handbook of Grounded Theory. London, Sage.

Bryman, A. (2007). "Effective Leadership in Higher Education: a literature review." Studies in Higher Education 32(6): 693-710. DOI: 10.1080/03075070701685114.

Charmaz, K. (2014). Constructing Grounded Theory. London, Sage.

Contu, A. and Willmott, H. (2003). "Re-Embedding Situatedness: The Importance of Power Relations in Learning Theory." Organization Science 14(3): 283-296.

Crawford, M. (2012). "Solo and Distributed Leadership: Definitions and Dilemmas." Educational Management Administration Leadership 40(5): 610-620. DOI: 10.1177/1741143212451175

Deem, R. and Brehony,K.J. (2005). "Management as ideology: the case of 'new managerialism' in higher education." Oxford Review of Education 31(2): 217-235. DOI: 10.1080/03054980500117827

Glaser, B. and Strauss, A. (1967). The discovery of grounded theory: strategies for qualitative research. Chicago, Aldine. 
Accepted version of: Jarvis, S. (2018). Practice-Focused, Constructivist Grounded Theory Methodology In Higher Education Leadership Research. In Theory and Method in Higher Education Research (Theory and Method in Higher Education Research; Vol. 4). Bingley: Emerald Group Publishing Ltd.. https://doi.org/10.1108/S2056-375220180000004012, https://doi.org/10.1108/S2056-375220180000004012

Huber, S. (2016). School Leadership Practices and Health: selected findings from a multimethod longitudinal school leadership study. BELMAS. P. Woods. Carden Park, Chester, BELMAS.

Hui, A. (2017). Variation and the intersection of practices. The Nexus of practices: connections, constellations and practitioners. A. Hui, T. Schatzki and E. Shove. London and New York, Routledge: 52-67.

Jarvis, S. (2017). The practice of authority in academic leadership/management. Department of Educational Research. Lancaster, Lancaster University. PhD.

Lave, J. and Wenger, E. (1991). Situated Learning, legitimate peripheral participation. Cambridge, Cambridge University Press.

Lempert, L. B. (2007). Asking Questions of the data: memo writing in the grounded theory tradition. SAGE Handbook of Grounded Theory. A. Bryant and K. Charmaz. London, SAGE Publications Ltd: 245-264.

Lipsky, M. (1980). Street level bureaucracy: dilemmas of the individual in public services. New York, Russell sage Foundation.

Lumby, J., Ed. (2012). What do we know about leadership in Higher Education? Review Papers. London, The Leadership Foundation for Higher Education.

Mason, J. (2002). Researching your own practice: the discipline of noticing. London, RoutledgeFalmer.

Nicolini, D. (2012). Practice Theory, Work and Organization: an introduction. Oxford, Oxford University Press.

Nicolini, D. (2017 ). Is small the only beautiful? The Nexus of Practices: connections, constellations and practitioners. A. Hui, T. Schatzki, R. and E. Shove. London and New York, Routledge: 98-113.

ONS (2015). Participation Rates In Higher Education: Academic Years 2006/2007 2014/2015 (Provisional). D. f. Education. London, DfE.

Raelin, J. (2016). "Imagine there are no leaders: Reframing leadership as a collaborative activity." Leadership 12(2): 131-158. DOI: 10.1177/1742715014558076

Raz, J., Ed. (1990). Authority. Readings in Social and Political Theory. Oxford, Basil Blackwell

Reckwitz, A. (2002). "Towards a theory of social practices: a development in culturalist theorizing." European Journal of Social Theory 5(2): 243-263. DOI:

$10.1177 / 13684310222225432$ 
Accepted version of: Jarvis, S. (2018). Practice-Focused, Constructivist Grounded Theory Methodology In Higher Education Leadership Research. In Theory and Method in Higher Education Research (Theory and Method in Higher Education Research; Vol. 4). Bingley: Emerald Group Publishing Ltd.. https://doi.org/10.1108/S2056-375220180000004012, https://doi.org/10.1108/S2056-375220180000004012

Robbins, L. (1963). Higher Education: Report of a Committee. Appendix 1: the demand for places in higher education. . London.

Schatzki, T., R. (1996). Social Practices: a Wittgensteinian approach to human activity and the social. Cambridge, cambridge University Press.

Schatzki, T., R. (2001). Practice mind-ed orders. The practice turn in comtemporary theory. T. Schatzki, R., K. Cetina, Knorr and E. Von Savigny. London and New York, Routledge: 4255.

Shove, E., Pantzar, M. and Watson, M. (2012). The dynamics of social practice: everyday life and how it changes. London, Sage.

Thomas, G. and James, D. (2006). "Reinventing grounded theory: some questions about theory, ground and discovery." British Educational Research Journal 32(6): 767-795. DOI: $10.1080 / 01411920600989412$

Tight, M. (2012). Researching Higher Education. Maidenhead, Open University Press.

Trowler, P. (2001). "Captured by the discourse? The socially constitutive power of New Higher Education Discourse in the UK." Organization 8(2): 183-201. DOI:

$10.1177 / 1350508401082005$

Trowler, P. (2013). "Practice-focused ethnographies of higher education: method/ological corollaries of a social practice perspective." European Journal of Higher Education 4(1). DOI: $10.1080 / 21568235.2013 .833485$

Watson, D. (2011). "Cassandra and the politicians: higher education and policy memory." Educational Review 63(4): 409-419. DOI: 10.1080/00131911.2011.603824

Watson, M. (2017). Placing power in practice theory. The Nexus of Practices: connections, constellations, practitioners. A. Hui, T. Schatzki, R. and E. Shove. London and New York, Routledge.

Weber, M. (2004). Politics as a Vocation. The Vocation Lectures. D. Owen and T. Strong, B. Indianipolis, Hackett Publishing.

Wilkinson, J. and Kennis, S. (2015). "Practice Theory: Viewing leadership as leading." Educational Philosophy and Theory 47(4342-358). DOI: 10.1080/00131857.2014.976928

Wittgenstein, L. (1953). Philosophical Investigations. Oxford, Blackwell.

Woods, P. (2016). "Authority, Power and Distributed Leadership." Management in Education 30(4): 155-160. DOI: 10.1177/0892020616665779 